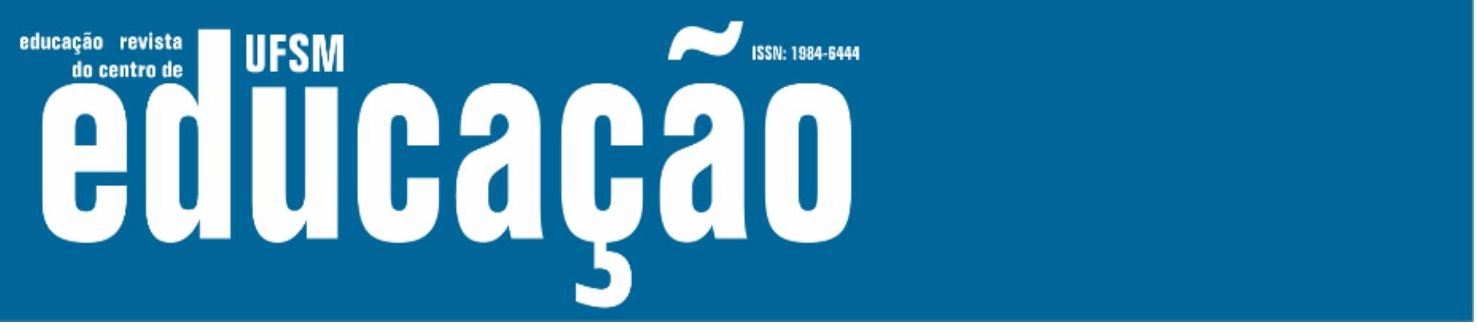

ISSN: 1984-6444 | http://dx.doi.org/10.5902/1984644441338

\title{
Notas sobre os saberes disciplinares do Curso Normal da Escola Superior de Educação Física do Rio Grande do Sul (1940-1956)
}

\author{
Notes on the disciplinary knowledge of the Normal Course of the School \\ of Physical Education of Rio Grande do Sul
}

\section{Tuany Defaveri Begossi}

Doutoranda da Universidade Federal do Rio Grande do Sul. Porto Alegre, Rio Grande do Sul, Brasil. tuany_begossi@hotmail.com - https://orcid.org/0000-0002-2596-5963

Janice Zarpellon Mazo

Professora Doutora da Universidade Federal do Rio Grande do Sul. Porto Alegre, Rio Grande do Sul, Brasil.

janice.mazo@ufrgs.br - https://orcid.org/0000-0002-8215-0058

Cibele Biehl Bossle

Docente do Sistema de Ensino Gaúcho, Porto Alegre, Rio Grande do Sul, Brasil. cibele.bossle@terra.com.br - https://orcid.org/0000-0003-3633-3483

Vanessa Bellani Lyra

Professora Doutora do Centro Universitário Estácio de Santa Catarina. São José, Santa Catarina, Brasil.

vblyra@ucs.br - https://orcid.org/0000-0001-9653-2930

Recebido em 26 de novembro de 2019

Aprovado em 03 de julho de 2020

Publicado em 28 de maio de 2021

\section{RESUMO}

O presente estudo tem por objetivo compreender como ocorreu a organização dos saberes disciplinares do Curso Normal, da Escola Superior de Educação Física (ESEF), do estado do Rio Grande do Sul, durante o período em que este permaneceu em atividade (1940-1956). A narrativa historiográfica, guiada por Certeau (2017) e Chartier (2017), foi sustentada pelos pressupostos teóricometodológicos dos saberes docentes, especialmente aqueles compreendidos por Desbiens (2005) e Tardif (2014) como saberes disciplinares e saberes curriculares. Este referencial foi articulado com a bibliografia sobre planejamento pedagógico, sobretudo aquela empregada por Libâneo (2012). O processo de análise e enfrentamento dos distintos documentos históricos utilizados pela pesquisa foi orientado pela técnica de análise documental, conforme descrita por Cellard (2012). Os resultados obtidos sustentaram a construção de uma leitura sobre a organização dos saberes disciplinares do Curso Normal de Educação Física da ESEF, os quais 


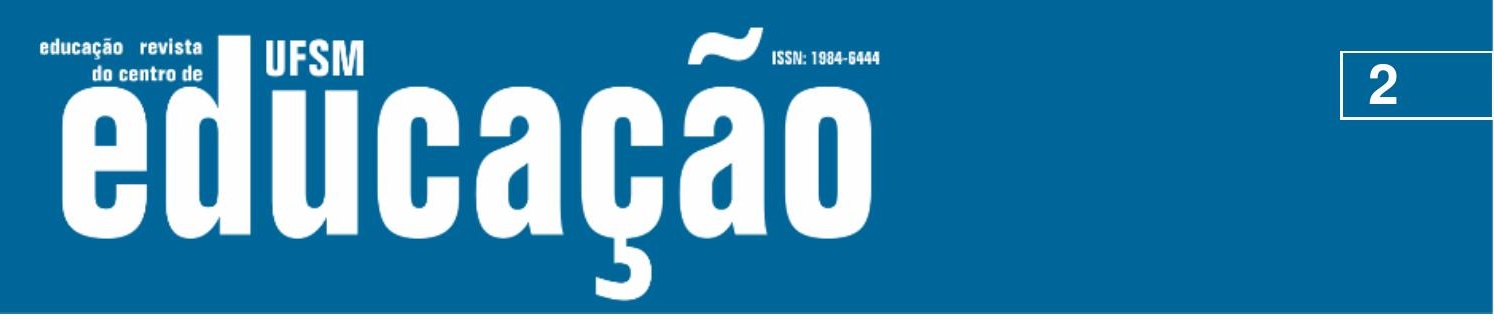

ISSN: 1984-6444 | http://dx.doi.org/10.5902/1984644441338

foram diferenciados, inicialmente, por suas características de ensino prático e teórico. Intrinsecamente a essas diferenciações, foi possível demarcar características do perfil profissional forjado pelo referido curso. Neste cenário, os(as) professores(as) que frequentaram e concluíram o Curso Normal de Educação Física na ESEF, ao inserirem-se nas escolas primárias, conduziram o ensino de uma Educação Física voltada ao saber fazer, característica esta que permeava a formação profissional da área, durante o período (1940-1957).

Palavras-chave: História da Educação Física; História da Educação; Ensino teórico e prático.

\section{ABSTRACT}

The present study aims to understand how an organization of disciplinary disciplines of the Normal Course, of the Escola Superior de Educação Física (ESEF), of the state of Rio Grande do Sul, occurred during the period in which the active activity (1940-1956). The historiographical narrative, guided by Certeau (2017) and Chartier (2017) was supported by the theoretical-methodological assumptions of teaching knowledge, especially those understood by Desbiens (2005) and Tardif (2014) as disciplinary knowledge and curricular knowledge. This reference was articulated with the bibliography on pedagogical planning, especially that used by Libâneo (2012). The analysis and confrontation process of the different historical documents used by the research was guided by the document analysis technique, as described by Cellard (2012). The results obtained supported the construction of a reading about an organization of the disciplinary knowledge of the Normal Physical Education Course of ESEF, which were differentiated by their practical and theoretical teaching characteristics. Intrinsically, these differentiations were possible to mark characteristics of the professional profile forged by the referred course. In this scenario, the teachers who attended and completed the Normal Course of Physical Education at ESEF, when inserting themselves in primary schools, led the teaching of a Physical Education focused on know how, a characteristic that permeated the professional training of the area, during the period (1940-1957).

Keywords: History of Physical Education; History of Education; Theoretical and practical teaching.

\section{Introdução}

${ }^{1}$ A Escola Superior de Educação Física (ESEF), do estado do Rio Grande do Sul, atual Escola de Educação Física, Fisioterapia e Dança (ESEFID), da Universidade Federal do Rio Grande do Sul, foi criada e vinculada ao Departamento 


\section{Althaห̧ão}

ISSN: 1984-6444 | http://dx.doi.org/10.5902/1984644441338

estadual de Educação Física (DEEF), no ano de 1940. O DEEF subordinava-se a, então, denominada Secretaria de Educação e Cultura do estado (SEC), e suas ações foram orientadas, inicialmente, pelo Regimento Interno², aprovado pelo Decreto no 811, de 2 de agosto de 1943 (RIO GRANDE DO SUL, 1943). Este documento, além de prever as responsabilidades do DEEF perante a administração da ESEF, também enunciava em suas linhas, orientações destinadas à organização do ensino da referida instituição.

A ESEF foi a primeira instituição de ensino superior a formar professores(as) civis de Educação Física, no estado do Rio Grande do Sul (MAZO, 2005a). As atividades acadêmicas iniciaram com o oferecimento do Curso Normal de Educação Física, cujo período de vigência compreendeu os anos de 1940 a 1956 (BEGOSSI, 2017). O referido curso pretendia especializar normalistas, ou seja, professores(as) que haviam obtido uma formação via Escola Normal, para trabalhar com a matéria ${ }^{3}$ de Educação Física no ensino primário. Assinalamos que, para além do Curso Normal de Educação Física, a ESEF passou a oferecer, a partir do ano de 1941, o Curso de Medicina de Educação Física e dos Desportos, o Curso de Técnica Desportiva e o Curso de Treinamento e Massagem, todos com duração de um ano cada, e o Curso Superior de Educação Física, com duração de dois anos (MAZO, 2005a).

A ESEF permaneceu sendo a única instituição de ensino superior, no estado, a formar professores(as) de Educação Física pelos 30 anos que se seguiram a sua fundação (LYRA, 2013). Nesta mesma direção, torna-se necessário destacarmos a significativa contribuição da ESEF para a construção do campo da formação de professores(as) da área, no Rio Grande do Sul, a partir do momento em que fora reconhecida, pelo governo federal, em 1939, como a única instituição apta, no estado, a emitir diplomas de formação profissional em Educação Física. Esta medida, segundo Lyra (2013, p. 149), "contribuiu para a construção da ideia de que a Educação Física era uma área de conhecimento que possuía seus próprios saberes". Diante disso, tão importante quanto a criação de instituições para formar professores(as) estava o estabelecimento de saberes disciplinares que demarcariam os modos de fazer e ensinar esta matéria nas escolas. 


\section{Autนaดูลิ}

ISSN: 1984-6444 | http://dx.doi.org/10.5902/1984644441338

Diante do exposto, o objetivo do presente estudo foi compreender como ocorreu a organização dos saberes disciplinares do Curso Normal da Escola Superior de Educação Física (ESEF), do estado do Rio Grande do Sul, durante o período em que este permaneceu em atividade (1940-1956). Ressaltamos que o recorte temporal da pesquisa parte do ano de 1940, quando o Curso Normal de Educação Física entrou em funcionamento juntamente com as demais atividades da ESEF, e encerra-se no ano de 1956, último ano de ocorrência do mencionado curso, visto que, em 1957, fora substituído pelo Curso de Educação Física Infantil.

\section{Referencial Teórico-Metodológico}

A narrativa historiográfica apresentada neste estudo foi construída a partir do cotejamento de documentos históricos - programas de ensino das disciplinas do Curso Normal de Educação Física da ESEF e Regimento Interno do DEEF -, para os quais se lançou um olhar analítico, sustentado pelos referenciais teóricometodológicos eleitos ao estudo. Deste modo, o discurso histórico produzido buscou apresentar uma leitura acerca da organização dos saberes disciplinares do Curso Normal de Educação Física da ESEF, na perspectiva de Certeau (2017) e Chartier (2017). De acordo com Certeau (2017, p. 8), a produção de um texto historiográfico, além de fabricar uma realidade, também faz parte desta, uma vez que "uma leitura do passado, por mais controlada que seja pela análise dos documentos, é sempre dirigida por uma leitura do presente". Nesta direção, também alicerçadas nas noções teóricas de Chartier (2017), compreendemos que a construção de uma narrativa historiográfica é sempre localizada social e culturalmente e, deste modo, é em função deste lugar que se "delineia uma topografia de interesses" (CERTEAU, 2017, p. 47), cuja subjetividade do pesquisador torna-se indissociável da escrita.

Assim, a construção da presente investigação foi norteada pelo contato com os documentos de pesquisa, bem como pelas análises que estes nos permitiram delinear acerca da realidade demarcada à investigação. A fim de guiar nosso olhar pelos documentos históricos, apoiamo-nos, inicialmente, na obra de Maurice Tardif, intitulada "Saberes docentes e formação profissional" (2014). O saber docente, 


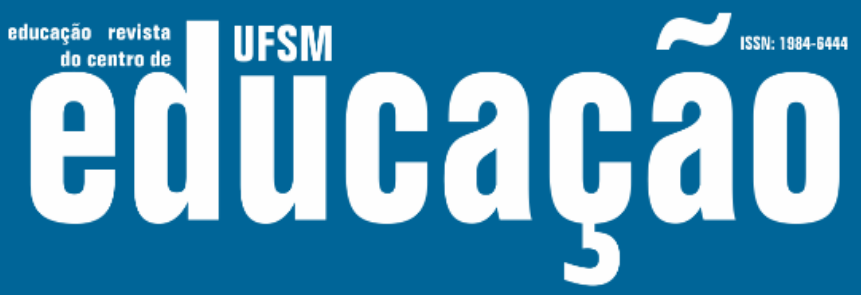

ISSN: 1984-6444 | http://dx.doi.org/10.5902/1984644441338

segundo Tardif (2014), é composto de vários outros tipos de saberes, podendo ser estes disciplinares, curriculares, profissionais e experienciais. Ao presente estudo interessaram, sobretudo, aqueles conceituados como disciplinares e curriculares. $\mathrm{O}$ primeiro corresponde aos diversos campos de conhecimento da sociedade que são integrados à universidade na forma de disciplinas; o segundo, por sua vez, apresenta-se, de modo concreto, na forma de programas de ensino, sistematizando os elementos necessários ao ensino (BORGES, 2005; TARDIF, 2014).

Para Tardif (2014, p. 38), os programas de ensino são saberes curriculares que constituem a representação concreta dos "discursos, objetivos, conteúdos e métodos a partir dos quais a instituição escolar categoriza e apresenta os saberes disciplinares". Desbiens (2005, p. 90), por sua vez, assinala que a importância dos programas de ensino é "imensa" em razão de "consistirem em prescrições que o docente deve considerar para a concepção, o planejamento e a avaliação dos aprendizados". Em vista do exposto, recorremos, de modo complementar, a bibliografia que trata sobre planejamento pedagógico para também orientar o nosso olhar aos documentos de pesquisa.

Libâneo (2012, p. 222) descreve planejamento como "um processo de racionalização, organização e coordenação da ação docente", que articula a atividade escolar com a problemática do contexto social. Para Fonseca (2015), o plano [programa de ensino] ${ }^{4}$ é a sistematização do planejamento. Desta forma, enquanto o plano [programa de ensino] pode ser compreendido como um produto provisório, passível de receber alterações, o planejamento vincula-se ao processo de permanente reflexão e tomada de decisão (VASCONCELOS, 2008).

Em relação ao documento que sistematiza o planejamento do ensino, Libâneo (2012, p. 232) menciona que este constitui-se em um "roteiro organizado das unidades didáticas para um ano ou semestre". De maneira detalhada, Fonseca (2015) evidencia que, no plano de ensino [programa de ensino], figuraram os objetivos educacionais, os conteúdos, os procedimentos de ensino e as formas de avaliação. Desta forma, os programas de ensino analisados no presente estudo são portadores de orientações de ordem pedagógica e, portanto, a semelhança do evidenciado nos conceitos teóricos descritos, apresentam elementos que 


\section{Aillbapẫ \\ 3}

ISSN: 1984-6444 | http://dx.doi.org/10.5902/1984644441338

sistematizaram a ação docente no Curso Normal de Educação Física da ESEF (1940-1956).

Os programas de ensino e o Regimento Interno do DEEF foram interpretados por meio da técnica de análise documental, conforme descrita por Cellard (2012). Em seguida, os resultados obtidos foram interpretados e apresentados através de uma narrativa historiográfica, organizada nos tópicos que seguem.

\section{A disposição dos saberes disciplinares em práticos e teóricos}

A fim de compreendermos a disposição dos saberes disciplinares fez-se necessário visualizar como estava estruturado o DEEF e, para tanto, analisar seu Regimento Interno. Em tal documento, consta que o DEEF estruturava-se em seis principais órgãos, a saber: I - Diretoria; II - Divisão de Ensino; III - Divisão de Biologia; IV - Divisão Técnica; V - Divisão Administrativa e VI - Escola de Educação Física (RIO GRANDE DO SUL, 1943). Para a presente investigação, dedicamo-nos a analisar as Divisões de Biologia e Divisão Técnica, visto que eram a esses órgãos e as suas respectivas seções que se vinculavam os(as) professores(as) catedráticos responsáveis pelo ensino dos saberes da ESEF. A composição de ambas as divisões encontram-se apresentadas na figura abaixo.

Figura 1 - Composição da Divisão de Biologia e da Divisão Técnica do DEEF

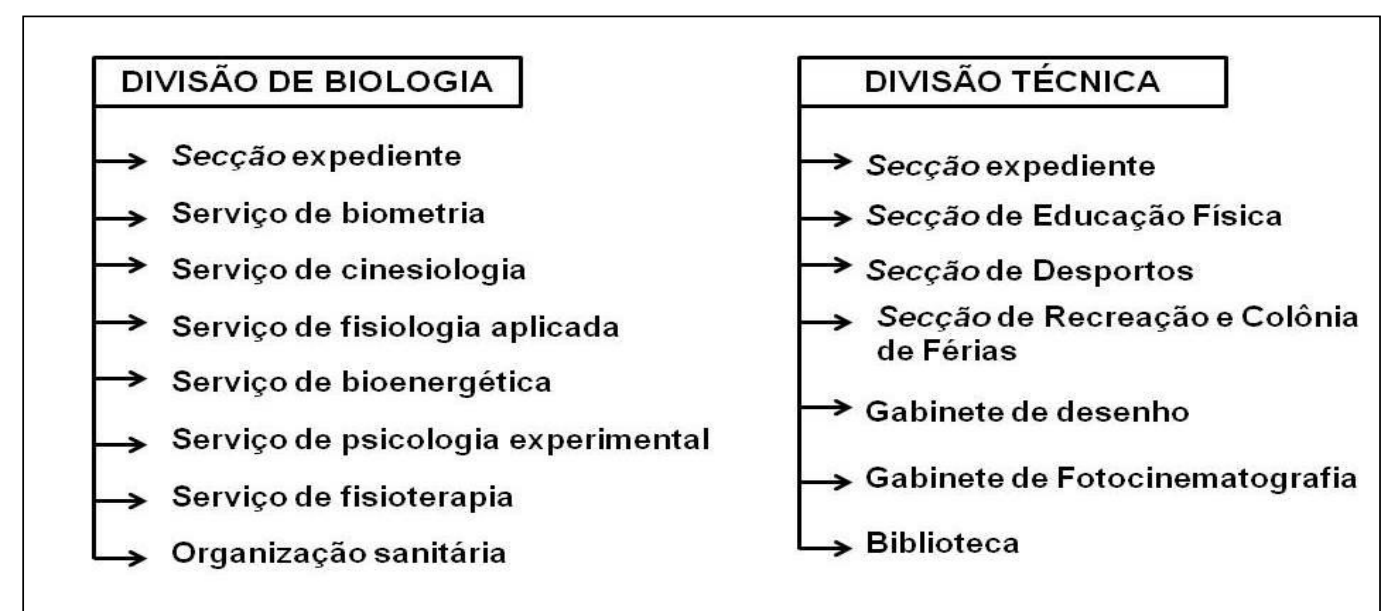

Fonte: Adaptado de Begossi (2017), elaborado com base no Regimento Interno do DEEF (RIO GRANDE DO SUL, 1943). 


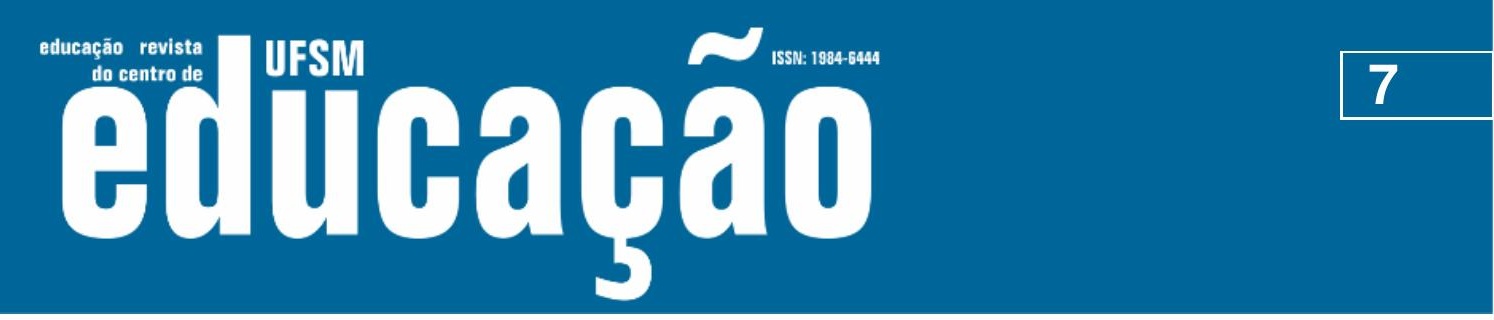

ISSN: 1984-6444 | http://dx.doi.org/10.5902/1984644441338

Importa destacarmos que esta disposição foi apresentada, inicialmente, no Título II, mais especificamente nos Capítulos IV e V, do Regimento Interno do DEEF (RIO GRANDE DO SUL, 1943). Essa mesma organização foi retomada no Título III, Capítulo II, do referido documento, para referir-se aos "funcionários e suas atribuições". Neste espaço, por sua vez, foi destacado no Artigo 56, que "Os Adjuntos das secções 5 de Biometria, Cinesiologia, Fisiologia aplicada, Psicologia experimental e Fisioterapia serão os professores catedráticos das respectivas cadeiras6". Ainda, no Artigo 58, evidenciava-se que "O Adjunto da secção de Educação Física e o da secção de Desportos serão escolhidos entre os professores catedráticos das cadeiras práticas" (RIO GRANDE DO SUL, 1943, p.5).

A análise ao conteúdo descrito sugere uma divisão entre os saberes que compunham o Curso Normal de Educação Física da ESEF, sobretudo ao que concerne às suas características de ensino. Conforme demonstrado no conteúdo explicitado no Artigo 58, havia uma relação de saberes portadores de um caráter de ensino classificado como prático. Essa assertiva faz-nos conceber, consequentemente, que os saberes elencados no Artigo 56, pertenceriam a um conjunto de cadeiras possuidoras de um viés teórico. Por este motivo, provavelmente, estavam localizadas em Divisões distintas dentro do DEEF.

De outro modo, tanto na figura trazida pelo presente estudo quanto na descrição dos conteúdos dos Artigos 56 e 58, do Regimento Interno do DEEF, demonstrou-se que os(as) professores(as) responsáveis pelo andamento dos saberes de caráter biológico vinculavam-se à Divisão de Biologia do DEEF. Por sua vez, aqueles responsáveis pelos saberes disciplinares caracterizados por um caráter prático ligavam-se à Divisão Técnica do DEEF, mais especificamente às seções de Educação Física e de Desportos (RIO GRANDE DO SUL, 1943). Com base nas informações apresentadas, podemos organizar os saberes disciplinares do Curso Normal de Educação Física da ESEF em dois eixos: a) Disciplinas biológicas, possuidoras de um caráter teórico e b) Disciplinas técnicas, dotadas de um caráter prático.

Ao primeiro eixo, referente às disciplinas teóricas, figuravam os saberes disciplinares do Curso Normal de Educação Física, organizados a partir da Divisão 


\section{Autตaดูão}

ISSN: 1984-6444 | http://dx.doi.org/10.5902/1984644441338

de Biologia, a saber: a) Anatomia Humana Aplicada; b) Biometria; c) Cinesiologia Aplicada; d) Fisioterapia; e) Higiene Aplicada e f) Socorros de Urgência (PROGRAMAS DE ENSINO, 1940). Ao segundo eixo, ou seja, aquele possuidor de características de ensino prático e vinculado à Divisão Técnica, figuraram os seguintes saberes disciplinares: a) Canto Coral; b) Desportos Aquáticos; c) Desportos de Ataque e Defesa; d) Desportos Terrestres Coletivos; e) Desportos Terrestres Individuais; f) Educação Física Geral - Feminina; g) Ginástica Rítmica; h) História da Educação Física e dos Desportos; i) Metodologia da Educação Física; j) Organização da Educação Física e dos Desportos; k) Ritmo e I) Tênis Feminino (PROGRAMAS DE ENSINO, 1940).

A partir desta organização dos saberes disciplinares do Curso Normal de Educação Física da ESEF foi possível compreendermos determinadas questões que se encontravam intrínsecas a esta disposição. A divisão dos saberes disciplinares em dois grupos distintos - teóricos e práticos - permitiu-nos o delineamento de questões estruturais vinculadas aos saberes disciplinares de cada um dos grupos, por meio da análise de seus programas de ensino. Tais características possibilitaram que adentrássemos espaços simbólicos estabelecidos por esta categorização, a fim de compreender nuances vinculadas às características estruturais demarcadas.

De modo específico, o delineamento das estruturas de cada um dos saberes disciplinares somente foi possível de ser realizado através da análise aos programas de ensino. Estes documentos pedagógicos dividiam-se em quatro partes. A primeira, apresentada sob a forma de cabeçalho, destacava o nome da instituição de ensino (Escola Superior de Educação Física), o Curso em questão (Curso Normal de Educação Física), seguido da escrita "Conteúdo Programático de x", no qual "x" referia-se ao saber disciplinar a que o programa de ensino tratava. Posteriormente, a segunda parte destinava-se a apresentar o(s) objetivo(s). Em seguida, na terceira parte, apresentava-se uma relação pormenorizada do conteúdo programático a ser desenvolvido. Na quarta e última parte, situada ao final do documento pedagógico, evidenciava-se o número de aulas, o material didático utilizado, os meios de verificação do aprendizado, os locais de realização das aulas, bem como a bibliografia utilizada para embasar os estudos (PROGRAMAS DE ENSINO, 1940). 


\section{Authaดูã}

ISSN: 1984-6444 | http://dx.doi.org/10.5902/1984644441338

Ressaltamos que, para esta investigação, detivemo-nos a analisar a estruturação dos programas de ensino focalizando, sobretudo, o número de grupos de conteúdos programáticos estabelecidos a cada saber, bem como a carga horária ou o número de aulas/sessões estabelecidos a cada um. Iniciemos, assim, tratando de especificidades acerca do primeiro eixo, relacionado às disciplinas biológicas, atravessadas por um caráter teórico.

Ao analisarmos a composição dos programas de ensino, dos saberes disciplinares que compõem o referido eixo, foi possível observarmos que apenas no documento pedagógico de Anatomia Humana Aplicada os objetivos não foram explicitados. Além disso, as informações relacionadas ao material didático, aos meios de verificação do aprendizado, aos locais das aulas, bem como à bibliografia, também não foram descritas. Constavam apenas os conteúdos programáticos a serem desenvolvidos, os quais totalizavam 14 grupos, bem como o total de 24 aulas/sessões, sendo este o menor número dentre os saberes orientados pela Divisão de Biologia do DEEF (PROGRAMAS DE ENSINO, 1940; RIO GRANDE DO SUL, 1943).

Nos programas de ensino dos saberes disciplinares de Biometria, Cinesiologia Aplicada e Fisioterapia, foi explicitada a totalidade de informações solicitadas. Todavia, diferiram no que concerne ao número de grupos de conteúdos programáticos, bem como no total de aulas/sessões. Enquanto os saberes de Biometria e Fisioterapia organizavam-se em torno de 19 grupos, a disciplina de Cinesiologia Aplicada era constituída por cinco. Apesar disso, o número de aulas de Cinesiologia Aplicada era superior ao de Biometria e Fisioterapia. Assim, enquanto o saber de Cinesiologia Aplicada contava com um total de 32 aulas e, portanto, caracterizava-se como a disciplina com o maior número de aulas deste eixo, as disciplinas de Biometria e Fisioterapia eram ambas compostas por 30 aulas. Ressaltamos ainda que o saber de Biometria, de modo específico, era orientado através de 17 aulas teóricas e 13 práticas (PROGRAMAS DE ENSINO, 1940).

Ainda tratando de caracterizar os saberes disciplinares do eixo vinculado à Divisão de Biologia foi possível localizarmos proximidades entre saberes disciplinares de Higiene Aplicada e Socorros de Urgência. Com exceção dos locais 


\section{त

ISSN: 1984-6444 | http://dx.doi.org/10.5902/1984644441338

de realização das aulas, os programas de ensino de ambas as disciplinas apresentaram todas as demais informações solicitadas. Tais saberes disciplinares diferiram, por sua vez, no número de grupos de conteúdos programáticos e também no total de aulas/sessões. Enquanto a disciplina de Higiene Aplicada contava com 14 grupos e o total de 29 aulas/sessões, Socorros de Urgência compunha-se de 13 grupos de conteúdos programáticos e de 30 sessões/aulas (PROGRAMAS DE ENSINO, 1940).

No quadro abaixo, é possível observarmos a relação de saberes disciplinares que compunham este eixo, bem como o respectivo número de grupos de conteúdos programáticos, seguido da quantidade de aulas/sessões de cada um.

Quadro 1 - Características estruturais dos programas de ensino orientados pela Divisão de Biologia do DEEF

\begin{tabular}{|c|c|c|c|c|}
\hline \multirow[b]{2}{*}{ Saberes disciplinares } & \multirow{2}{*}{$\begin{array}{c}\text { № de grupos de } \\
\text { conteúdos } \\
\text { programáticos }\end{array}$} & \multicolumn{3}{|c|}{ № de aulas/sessões } \\
\hline & & Total & Teóricas & Práticas \\
\hline Anatomia Humana Aplicada & 14 & 24 & - & - \\
\hline Biometria & 19 & 30 & 17 & 13 \\
\hline Cinesiologia Aplicada & 5 & 32 & - & - \\
\hline Fisioterapia & 19 & 30 & - & - \\
\hline Higiene Aplicada & 14 & 29 & - & - \\
\hline Socorros de Urgência & 13 & 30 & - & - \\
\hline
\end{tabular}

Fonte: Adaptado de Begossi (2017), com base nos programas de ensino (1940)

Com relação à composição dos programas de ensino, dos saberes disciplinares que compunham o segundo eixo relacionado aos saberes técnicos, dotados de um caráter prático de ensino, foi possível demarcarmos que Canto Coral e Metodologia da Educação Física, apenas não descreveram em seus documentos pedagógicos o material didático utilizado para o desenvolvimento das aulas. Todas as demais informações (objetivos, número de grupos de conteúdos programáticos, número de aulas/sessões, meios de verificação do aprendizado, locais das aulas e bibliografia) foram evidenciadas. Com relação aos demais saberes disciplinares que compunham este eixo de análise, notamos que todos apresentaram a totalidade de informações elencadas (PROGRAMAS DE ENSINO, 1940). 


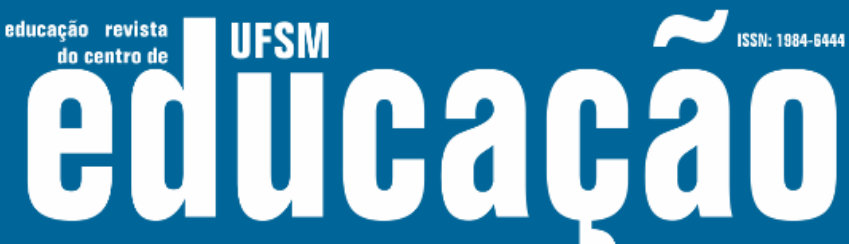

ISSN: 1984-6444 | http://dx.doi.org/10.5902/1984644441338

Para além de auxiliar no destaque com relação à presença ou não de determinadas informações nos programas de ensino, a análise da estrutura destes documentos possibilitou compreendermos os tempos que cada disciplina ocupou na formação empreendida pelo Curso Normal de Educação Física da ESEF. Diante disso, ao determo-nos na análise das informações contidas no espaço referente ao "número de aulas/sessões", demarcamos que o saber disciplinar de Canto Coral contava com um total de 10 aulas para o desenvolvimento de 18 segmentos de conteúdos. De forma significativamente distinta, a disciplina de Educação Física Geral - Feminina, contava com 129 aulas para o cumprimento de seu programa de ensino, composto por 20 grupos de conteúdos. De modo similar, o saber de Ginástica Rítmica contava com 96 aulas, para o desenvolvimento de seu programa, composto por 13 segmentos de conteúdo.

Diante do exposto, podemos ressaltar que, apesar de a disciplina de Canto Coral ser a que menos dispunha de aulas para o cumprimento de seu programa, era, ao mesmo tempo, a que possuía o maior número de grupos de conteúdos programáticos pré-estabelecidos. Abaixo, da mesma forma que o quadro sistematizado para o primeiro eixo, elaboramos outro para melhor visualizarmos os dados acima descritos.

Quadro 2 - Características estruturais dos Programas de Ensino orientados pela Divisão Técnica do DEEF

\begin{tabular}{|c|c|c|c|}
\hline \multicolumn{2}{|c|}{ Saberes disciplinares } & $\begin{array}{l}\text { № de grupos de } \\
\text { conteúdos } \\
\text { programáticos }\end{array}$ & $\begin{array}{l}\text { № de aulas/ } \\
\text { sessões }\end{array}$ \\
\hline \multicolumn{2}{|l|}{ Canto Coral } & 18 & 10 \\
\hline \multicolumn{2}{|c|}{ Desportos Aquáticos - Remo } & 5 & 15 \\
\hline \multicolumn{2}{|c|}{ Desportos Ataque e Defesa } & 8 & 65 \\
\hline \multirow{3}{*}{$\begin{array}{l}\text { Desportos Terrestres } \\
\text { Coletivos }\end{array}$} & Basquetebol & 4 & 45 \\
\hline & Futebol & 6 & 30 \\
\hline & Volibol & 5 & 45 \\
\hline \multirow{4}{*}{$\begin{array}{l}\text { Desportos Terrestres } \\
\text { Individuais }\end{array}$} & Corridas & 5 & 15 \\
\hline & $\begin{array}{l}\text { Ginástica de aparelhos e } \\
\text { levantamento de pesos e halteres }\end{array}$ & 2 & 30 \\
\hline & Lançamentos & 6 & 17 \\
\hline & Saltos femininos & 5 & 15 \\
\hline \multicolumn{2}{|c|}{ Educação Física Geral - Feminina } & 20 & 129 \\
\hline \multicolumn{2}{|c|}{ Ginástica Rítmica } & 13 & 96 \\
\hline \multicolumn{2}{|c|}{ História da Educação Física e dos Desportos } & 10 & 24 \\
\hline
\end{tabular}




\section{Nusm Eutbapga}

ISSN: 1984-6444 | http://dx.doi.org/10.5902/1984644441338

Continuação Quadro 2 - Características estruturais dos Programas de Ensino orientados pela Divisão Técnica do DEEF

\begin{tabular}{|l|c|c|}
\hline \multicolumn{1}{|c|}{ Saberes disciplinares } & $\begin{array}{c}\text { № de grupos de } \\
\text { conteúdos } \\
\text { programáticos }\end{array}$ & $\begin{array}{c}\text { № de aulas/ } \\
\text { sessões }\end{array}$ \\
\hline Metodologia da Educação Física & 3 & 45 \\
\hline Organização da Educação Física e dos Desportos & 15 & 20 \\
\hline Ritmo & 4 & 15 \\
\hline Tênis Feminino & 3 & 30 \\
\hline
\end{tabular}

Fonte: Adaptado de Begossi (2017), com base nos programas de ensino (1940)

Conforme foi possível percebermos, nos programas de ensino de ambos os grupos de saberes disciplinares, existem distinções, especialmente, no que concerne à organização de sua estrutura. Este fato justifica-se, sobretudo, em razão de não haver um órgão, no interior do DEEF, responsável pela elaboração de tais documentos pedagógicos. Ao invés disso, destacamos que eram os(as) próprios(as) professores(as) catedráticos(as) das disciplinas que planejavam suas cadeiras e aulas, disponibilizando esta estruturação por meio dos programas de ensino (RIO GRANDE DO SUL, 1943; BRASIL, 1939). Portanto, era compreensível que a lógica interna de cada um desses materiais diferisse.

A partir das considerações de Borges (2005), Desbiens (2005), Tardif (2014) e Fonseca (2015), é possível demarcarmos o papel significativo que um planejamento, sistematizado na forma de programas de ensino, representa para a organização do ensino de uma instituição. Tais documentos de orientação pedagógica possibilitam a articulação interna dos saberes disciplinares, por meio da relação entre seus conteúdos programáticos e também uma articulação externa, ou seja, a relação que estes saberes estabelecem com os demais que compõem o currículo de um curso de formação.

Acerca do papel desempenhado pelos(as) docentes na elaboração e também na aplicação/ensino dos conteúdos elencados, destacamos que esta orientação foi prevista, inicialmente, por meio do Decreto-Lei 1.212, de 19397. No Artigo 29 da referida normativa, estava posto que "para cada disciplina haverá um programa que será elaborado pelo professor catedrático dela encarregado e deverá ter a aprovação do Conselho Técnico Administrativo8" (BRASIL, 1939, p. 5, grifo nosso). 


\section{Wism Autlbahat

De maneira complementar, o Regimento Interno do DEEF (RIO GRANDE DO SUL, 1943) previa um ato de fiscalização para averiguação do cumprimento das informações contidas no planejamento e, especialmente, das sequências de aprendizado. A responsabilidade deste ato, por conseguinte, recaía sobre a Divisão de Ensino do DEEF, mais especificamente a Seção Didática. No Artigo 12, parágrafo IX, destacava-se que:

A Secção Didática, dirigida pelo respectivo adjunto, compete organizar e manter em dia, em livros especiais, quadros demonstrativos da progressão das aulas teóricas e práticas, com um mapa alterado diariamente, de maneira a poder informar o Chefe da Divisão do adiantamento do ensino em determinada matéria, para efeito de fiscalização do cumprimento dos programas (RIO GRANDE DO SUL, 1943, p. 3, grifos nossos).

O trecho do Regimento Interno do DEEF exposto acima, para além de reafirmar a divisão dos saberes disciplinares em teóricos e práticos, ainda traz, intrinsecamente ao seu discurso, a demarcação de um tempo para o cumprimento dos conteúdos a serem ensinados. Diante deste ponto, torna-se perceptível que, apesar de a organização interna dos conteúdos não seguir uma única lógica, visto que cada professor(a) organizava seu próprio programa de aulas, os tempos que cada saber disciplinar dispunha eram previamente demarcados. Portanto, por meio da análise específica ao número de aulas/sessões que cada saber disciplinar dispunha foi possível estabelecermos sua representatividade no interior do Curso Normal de Educação Física da ESEF.

\section{Orientação prática e teórica dos saberes disciplinares}

O delineamento das considerações apresentadas no tópico anterior, para além de analisar a estrutura proposta nos programas de ensino, dos saberes disciplinares do Curso Normal da ESEF, também evidenciou que o número de aulas que compunha a Divisão Técnica era significativamente superior ao da Divisão de Biologia. Os saberes disciplinares que compuseram o segundo eixo e, portanto, possuidores de um caráter de ensino predominantemente prático perfaziam um total 


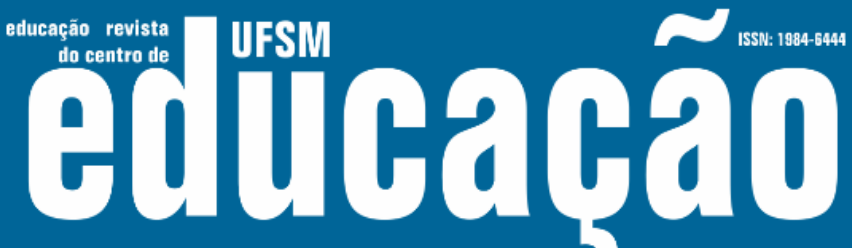

ISSN: 1984-6444 | http://dx.doi.org/10.5902/1984644441338

um aumento no número de professores(as) com formação específica em Educação Física: de 16, na década de 1940, para 24, na década de 1950 (BEGOSSI, 2017). Os(as) docentes que ingressaram, posteriormente, passaram a atuar como responsáveis e/ou auxiliares de determinadas disciplinas da ESEF.

Uma das justificativas para que novos(as) professores(as) passassem a compor o grupo de docente da instituição encontra-se no estudo de Mazo (2005b). A autora registrou que grande parte desses(as) professores(as) havia se formado nos cursos oferecidos pela própria instituição e foram convidados(as) a compor o quadro docente. Como traço comum desse grupo destacava-se o percurso esportivo e a atuação enquanto atletas em clubes do estado do Rio Grande do Sul. Esta característica de ter vivenciado um passado esportivo, por consequência, remetenos ao conceito de "saberes experienciais", abordado por Maurice Tardif (2014, p. 38). Para o autor, os saberes experienciais podem ser traduzidos como aqueles saberes ligados ao trabalho prático. Estes, por sua vez, são temporais, pois "são construídos e dominados progressivamente durante um período de aprendizagem variável, de acordo com cada ocupação" (TARDIF, 2014, p. 58).

Em sua obra "Saberes docentes e formação profissional", Tardif (2014) reserva o segundo capítulo para tratar dos saberes do tempo e da aprendizagem vinculados, de modo particular, ao trabalho do professor. Nesta direção, ao dar destaque às principais características do saber experiencial, o autor evidencia a relação de dependência deste com a atuação prática. Segundo Tardif (2014, p. 109), o saber experiencial é adquirido por meio dos aprendizados obtidos nas distintas vivências pelas quais o professor passou em momentos diferentes de sua trajetória, seja através da "história de vida, da carreira ou mesmo de outros trabalhos efetuados".

Diante disso, sugere-se que as alterações ocorridas no currículo da ESEF podem ter configurado uma das motivações para a inserção de docentes que já possuíssem em seu repertório determinados saberes experienciais obtidos, especialmente, por meio da vivência com a educação física e com o esporte, na condição de atletas. As experiências anteriormente obtidas também podem ter auxiliado os(as) próprios(as) professores(as) contratados na concepção de seu 


\section{Althaห̧ão}

ISSN: 1984-6444 | http://dx.doi.org/10.5902/1984644441338

trabalho enquanto docentes da ESEF. Assim, mesmo que a lógica ocorrida na ESEF, neste caso, tenha sido a inversa daquela proposta por Tardif (2014), na qual o autor destaca que a formação teórica antecede a formação prática, acreditamos que os saberes experienciais selecionados e inseridos na grade disciplinar através de seus(uas) docentes tenham sido interessantes tanto para a instituição quanto para os(as) próprios(as) professores(as) e alunos(as).

Deste modo, a dimensão prática dos saberes disciplinares parece ter assumido, na formação de professores(as) da ESEF e, de modo específico, no Curso Normal de Educação Física, um lugar privilegiado. Se inicialmente foi possível assinalarmos a superioridade de aulas destinadas a estes conteúdos em detrimento daqueles caracterizados como teóricos, o que percebemos ao longo da construção deste estudo foi a consolidação de uma formação técnico-prática. Esta característica da formação foi uma constante em diversos aspectos da Escola e manifestou-se, entre outras ocasiões, através da demarcação de normas, como os exames práticos para ingresso, ou mesmo por meio da inclusão de professores(as) atletas no quadro docente. Assim, tais elementos sustentaram um discurso que já havia sido anunciado através da predominância do ensino de determinados saberes disciplinares permeados por tal peculiaridade.

\section{Considerações finais}

O presente estudo buscou compreender como ocorreu a organização dos saberes disciplinares do Curso Normal da Escola Superior de Educação Física (ESEF), do estado do Rio Grande do Sul, durante o período em que este permaneceu em atividade (1940-1956). A partir da análise aos documentos históricos, construímos uma narrativa historiográfica, sustentada pelos pressupostos teórico-metodológicos dos saberes docentes, especialmente daqueles identificados como disciplinares e curriculares (BORGES, 2005; DESBIENS, 2005; TARDIF, 2014) e articulada com a bibliografia sobre planejamento pedagógico (LIBÂNEO, 2012; VASCONCELOS, 2008; FONSECA, 2015). Ao contrapor os distintos materiais de pesquisa, tornou-se possível construir uma leitura acerca da organização dos 


\section{Authaดูã}

ISSN: 1984-6444 | http://dx.doi.org/10.5902/1984644441338

saberes disciplinares do Curso Normal de Educação Física da ESEF.

Os indícios apresentados pelos documentos históricos demarcaram a organização dos saberes em dois eixos: um composto por disciplinas biológicas, possuidoras de um caráter de ensino teórico e o outro, constituído por disciplinas técnicas, dotadas de um caráter prático de ensino. Os mencionados grupos, para além de diferenciarem-se em suas formas de ensino, também distinguiam os docentes responsáveis em duas categorias. Desse modo, professores médicos e militares encarregavam-se de arquitetar os programas de ensino e, ao mesmo tempo, lecionar os saberes teóricos e práticos, respectivamente.

Intrinsecamente a tais diferenciações estruturais, circunscreviam-se, nos programas de ensino, os tempos destinados a cada um dos saberes disciplinares, os quais, em sua totalidade, compunham o arranjo mais geral da formação empreendida pelo Curso Normal de Educação Física da ESEF. Assim, a superioridade de aulas/sessões destinadas aos saberes técnicos determinava, consequentemente, o próprio perfil da formação de professores(as) empreendida pelo referido curso, o qual alocava aos conteúdos relacionados a dimensão do fazer um lugar de proeminência frente àqueles caracterizados como teóricos.

Destarte, a compreensão de elementos relacionados à organização dos saberes disciplinares do Curso Normal de Educação Física da ESEF permitiu-nos adentrar em um espaço educacional e demarcar, para além de suas formas de ensino, os próprios contornos que balizavam a formação profissional que estava sendo forjada. Desse modo, os(as) docentes formados(as) pelo referido Curso levavam, às escolas primárias, o ensino de uma Educação Física voltada ao saber fazer, característica que demarcava a própria formação profissional da área naquele período (1940-1957). Diante disso, nossos esforços foram concebidos no sentido de registrar, mesmo que de modo parcial e lacunar (CERTEAU, 2017), características da arquitetura de saberes disciplinares do Curso Normal de Educação Física da ESEF, buscando construir um discurso histórico e almejando contribuir para com a História da Educação e História da Educação Física brasileira. 


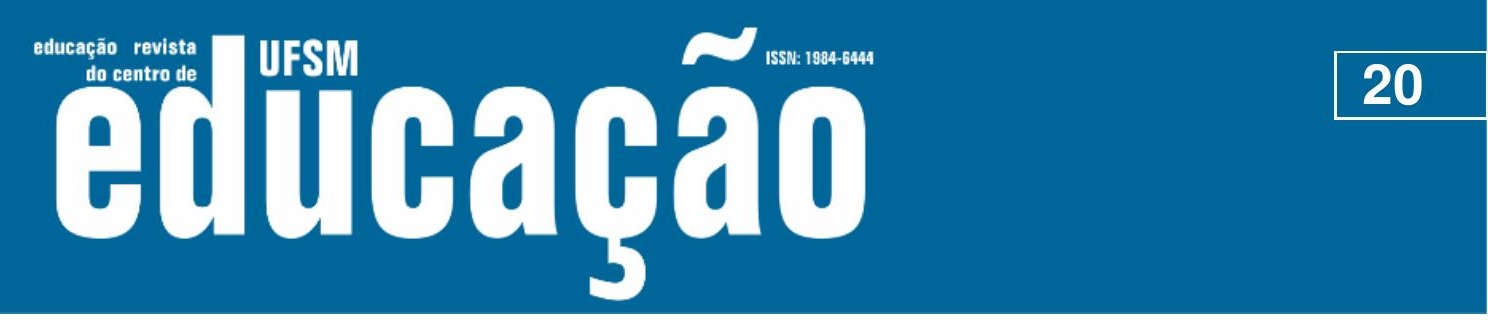

ISSN: 1984-6444 | http://dx.doi.org/10.5902/1984644441338

LYRA, Vanessa Bellani. A Criação da Escola Superior de Educação Física do Rio Grande do Sul: Formação de professoras(es) para a construção do campo (1940-1970). 2013. 265f. Tese (Doutorado), Escola de Educação Física, Universidade Federal do Rio Grande do Sul, Porto Alegre, 2013.

MAZO, Janice Zarpellon. Memórias da Escola Superior de Educação Física da Universidade Federal do Rio Grande do Sul (ESEF/UFRGS): um estudo do período de sua fundação até a federalização (1940-1969). Revista Movimento, Porto Alegre, v.11, n.1, p. 143-167. Jan/abr. 2005a.

MAZO, Janice Zarpellon; PEREIRA, Priscila Goulart (Org). Escola de Educação Física da Universidade Federal do Rio Grande do Sul - ESEF-UFRGS. Atlas do Esporte no Brasil. Rio de Janeiro: Shape, 2005b. p. 102.

PROGRAMAS DE ENSINO. Escola Superior de Educação Física. 1940.

RIO GRANDE DO SUL. Decreto n. 811 de 2 de agosto de 1943. Aprova o Regimento Interno do Departamento de Educação Física. Diário Oficial do estado do Rio Grande do Sul. Porto Alegre, 5 de agosto de 1943.

TARDIF, Maurice Tardif. Saberes Docentes e Formação Profissional. 17ª Ed. Rio de Janeiro: Vozes, 2014.

VASCONCELLOS, Celso dos Santos. Planejamento: projeto de ensinoaprendizagem e projeto político-pedagógico. São Paulo: Libertad, 2008.

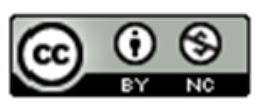

This work is licensed under a Creative Commons Attribution-NonCommercial 4.0 International (CC BY-NC 4.0)

\section{Notas}

\footnotetext{
${ }^{1} \mathrm{O}$ presente trabalho foi realizado com apoio da Coordenação de Aperfeiçoamento de Pessoal de Nível Superior - Brasil (CAPES) - Código de Financiamento 001.

2 Disponível em: (https://www.lume.ufrgs.br/handle/10183/110300). Acesso em: 30 out. 2019.

${ }^{3}$ O termo matéria era empregado para designar o que chamamos de disciplina. No tempo presente, o termo empregado na área da Educação é componente curricular.

${ }^{4}$ Os documentos históricos eleitos para pesquisa foram interpretados enquanto produções históricas e culturais, concebidas em determinado tempo e espaço. Desta forma, a análise destes documentos deu-se sem perder a perspectiva de que qualquer discurso é datado e, portanto, julgamos necessário mantermo-nos fiéis às terminologias empregadas, para evitarmos anacronismos na construção do discurso. Assim, optamos por manter o termo programas de ensino para denominar o documento que traz a relação de conteúdos programáticos, objetivos, métodos, número de aulas, materiais didáticos, meios de verificação de aprendizado e bibliografia de
} 


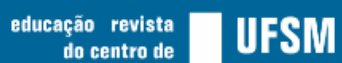 Allibahá}

ISSN: 1984-6444 | http://dx.doi.org/10.5902/1984644441338

cada um dos saberes disciplinares do Curso Normal de Educação Física da ESEF. Sublinhamos que, no tempo presente, tais documentos denominam-se planos de ensino.

${ }^{5}$ Ressaltamos que optamos por manter a grafia das palavras conforme aparecem nos documentos históricos consultados.

${ }^{6} \mathrm{O}$ termo cadeira era empregado para designar o que chamamos no tempo presente de disciplina ou de componente curricular.

${ }^{7}$ O referido Decreto-Lei criou, na Universidade do Brasil, a Escola Nacional de Educação Física e Desportos e deu outras providências (BRASIL, 1939).

${ }^{8}$ O Conselho Técnico Administrativo era um órgão consultivo do DEEF para o estudo e solução de questões administrativas e financeiras, devendo colaborar em todas as demais atribuições da Diretoria da Escola. 